\title{
Surgical lung biopsy for diffuse pulmonary disease: Experience of 196 patients
}

\author{
Yung-Chie Lee, MD, PhD, ${ }^{a}$ Chen-Tu Wu, MD, ${ }^{b}$ Hsao-Hsun Hsu, MD, ${ }^{a}$ Pei-Ming Huang, MD, a and Yih-Leong Chang, MD
}

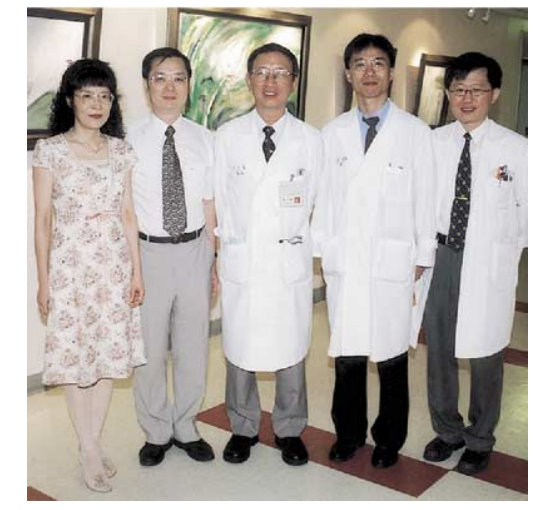

Left to right: Chang, Wu, Lee, Hsu, Huang
From the Departments of Surgery ${ }^{\mathrm{a}}$ and $\mathrm{Pa}$ thology, ${ }^{\mathrm{b}}$ National Taiwan University Hospital and National Taiwan University College of Medicine, Taipei, Taiwan.

Received for publication June 2, 2004; revisions received July 16, 2004; accepted for publication July 21, 2004.

Address for reprints: Yih-Leong Chang, MD, 6F-1, 99 Section 3, Roosevelt Rd, Taipei 106, Taiwan (E-mail: damu@ha.mc.ntu.edu.tw).

J Thorac Cardiovasc Surg 2005;129:984-90

$0022-5223 / \$ 30.00$

Copyright (C) 2005 by The American Association for Thoracic Surgery

doi:10.1016/j.jtcvs.2004.07.033
Objective: Surgical lung biopsy is considered the final method of diagnostic modality in patients with undiagnosed diffuse pulmonary disease. Nevertheless, the effect of surgical lung biopsy on the diagnosis, treatment, and outcome of the patient still remains controversial. This study reviewed the experiences of surgical lung biopsies in 196 consecutive patients during the past 7 years.

Methods: Surgical lung biopsy was performed after achievement of general anesthesia through video-assisted thoracoscopic surgery or a $7-\mathrm{cm}$ minithoracotomy. Biopsy specimens were swabbed for aerobic and anaerobic bacterial, fungal, and mycobacterial cultures. The sections of specimens were routinely stained with hematoxylin and eosin, and acid-fast, Gomori methenamine silver, Gram stain, or other special stains were added if necessary.

Results: The pathologic diagnosis after surgical lung biopsy included infection $(30.6 \%)$, interstitial pneumonia or fibrosis $(21.9 \%)$, diffuse alveolar damage (17.3\%), neoplasm (13.3\%), autoimmune diseases (8.2\%), and others (8.2\%). After surgical lung biopsy, $165(84.2 \%)$ patients had changes in their therapy, 124 (63.3\%) patients had clinical improvement of their conditions, and 119 (60.7\%) patients survived to hospital discharge. Comparison between immunocompromised and immunocompetent patients showed that diagnosis of infection was significantly higher $(P<.01)$ in the former group $(41.2 \%$ vs $20.2 \%)$. In addition, there was no significant difference in the distribution of diagnosis and rate of change in therapy between the respiratory failure and nonrespiratory failure groups. However, the rates of response to therapy and patient survival were significantly lower in the respiratory failure group (51.2\% and $41.5 \%)$ than in the nonrespiratory failure group (71.9\% and $78.1 \%, P<.05)$. There was no surgical mortality directly related to the procedure. The surgical morbidity rate was $6.6 \%$.

Conclusion: Surgical lung biopsy is a safe and accurate diagnostic tool for diffuse pulmonary disease. For a large proportion of the patients, change of therapy and then clinical improvement can be achieved after surgical lung biopsy. Surgical lung biopsy should be considered earlier in patients with undiagnosed diffuse pulmonary disease, especially when the respiratory condition is deteriorating.

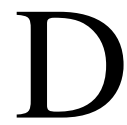
iffuse pulmonary disease (DPD) is the result of a variety of causes and is usually accompanied by a greater or lesser degree of respiratory failure that sometimes becomes a respiratory emergency. ${ }^{1-3}$ The majority of patients are initially given diagnoses on the basis of images and noninvasive or minimally invasive diagnostic procedures, such as echocardiography- or computed tomography-guided biopsy, transbronchoscopic biopsy, or lavage. Nevertheless, definitive diagnosis of lung lesions can sometimes not be made because of the inaccessibility of the true lesion or the inadequacy of the sample size. ${ }^{4-7}$ Surgical lung biopsy (SLB) is considered the final diagnostic modality to be used in patients with undiagnosed DPD. However, SLB has still been associated with substantial mor- 
bidity and mortality, even with advances in surgical techniques and respiratory care. ${ }^{7,8}$ The effect of SLB on the diagnosis, treatment, and outcome of the patient still remains controversial. ${ }^{7,9,10}$ In this study we retrospectively reviewed the experiences of SLBs in 196 consecutive patients in our institution during the past 7 years and looked specifically at the distribution of diagnosis, effect on therapy, and outcome of patients after SLB. The purpose of this study was to determine whether SLB is worthwhile and for which groups and when this procedure was more likely to benefit patients.

\section{Patients and Methods}

During the period from November 1995 through March 2003, a total of 196 patients with undiagnosed DPD underwent an open lung biopsy (SLB) for the purposes of tissue diagnosis. The medical records of these patients were retrospectively reviewed. These included the following: demographic data; underlying condition; clinical features; chest image study; status of respiratory function; specific diagnostic test, including sputum examination and culture; bronchoscopic examination; and related procedures, such as bronchial lavage or transbronchial biopsy. The duration from onset of symptoms to the date of SLB in each patient was also collected.

The patients were classified as immunocompromised, including (1) a primary diagnosis of malignancy for which the patient received chemotherapy, radiation, or surgical intervention; (2) receipt of organ transplantation with immunosuppressive therapy; (3) diagnosis of collagen vascular disease or other autoimmune diseases requiring corticosteroid or immunosuppressive therapy; (4) presence of AIDS; and (5) presence of chronic renal failure. On the other hand, according to the respiratory status, the patients were defined as the respiratory failure group if they had symptoms of respiratory insufficiency, a respiration rate of greater than 30

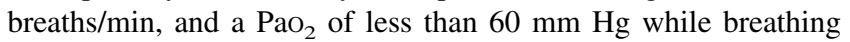
room air and required supplemental oxygen or ventilator support before SLB.

SLB was performed after achievement of general anesthesia through video-assisted thoracoscopic surgery (VATS) or a 7-cm minithoracotomy, which depended on the patient's tolerance for single-lung ventilation. The site and number of lung biopsy specimens were determined by the findings on the chest radiographs or the computed tomographic scans. Usually, 1 or 2 biopsy specimens, triangular in shape, 2 to $3 \mathrm{~cm}$ in each margin, were obtained. For VATS biopsy, 1 or 2 Endo GIA staples (Auto Suture Company Division, U.S. Surgical, Norwalk, Conn) were used for securing the pulmonary margins. For minithoracotomy, the lung specimen was cut off after clamping proximally, and tissue was secured by 2 rows of running sutures with 4-0 chromic catgut sutures. Biopsy specimens were swabbed for aerobic and anaerobic bacterial, fungal, and mycobacterial cultures. The specimens were then sent to the pathologist for freezing and permanent sectioning. Sections were routinely stained with hematoxylin and eosin. Acid-fast, Gomori methenamine silver, Gram stain, or other special stains were added if necessary. The pathologic diagnosis of SLB was obtained. The operative morbidity and mortality were recorded. The clinical diagnosis before the biopsy was compared with the pathologic diagnosis of SLB. Three items of variables were evaluated for each patient. Change in therapy indicated
Table 1. Underlying diseases in immunocompromised patients

\begin{tabular}{lc}
\hline Underlying disease & $\begin{array}{c}\text { No. of } \\
\text { patients }\end{array}$ \\
\hline Neoplastic disease & 63 \\
Leukemia & 31 \\
Solid tumors & 19 \\
Lymphoma & 12 \\
Multiple myeloma & 1 \\
Collagen or autoimmune disease & 11 \\
Dermatomyositis & 4 \\
Systemic lupus erythematosus & 3 \\
Polymyositis & 1 \\
Membranous glomerulonephritis & 1 \\
Giant cell arteritis & 1 \\
Behcet disease & 1 \\
Transplant recipient & 7 \\
Myelosuppressive diseases & 8 \\
Aplastic anemia & 3 \\
Myelodepressive syndrome & 3 \\
Fanconi syndrome & 1 \\
Thalassemia & 1 \\
Acquired immunodeficiency syndrome & 4 \\
Chronic renal failure & 3 \\
Ectopic ACTH hypersecretion & 1 \\
Total & 97 \\
\hline ACTH Adrenocortcotopic hormone.
\end{tabular}

ACTH, Adrenocorticotropic hormone.

that the original therapy had changed or stopped. Response to therapy meant imaging and clinical improvements after the change in therapy. Survival was interpreted as patient survival and discharge from the hospital. Statistical analysis was done with the $\chi^{2}$ test for the purposes of comparison between groups.

\section{Results}

In total, 196 patients underwent SLB for DPD during the study period. Eighty-seven patients were female, and 109 patients were male. The average age was 48.5 years (range, 6 months to 86 years). Among the 196 patients, 97 were immunocompromised, and 99 were not. The distribution of underlying diseases in the immunocompromised patients is shown in Table 1. Among them, a total of 51 patients had hematologic diseases, including neoplastic or myelosuppressive disorders, and 32 of them had previously undergone bone marrow transplantation (BMT). The duration from BMT to the development of DPD varied from 0.5 to 44 months, with a mean of 3.2 months. According to the patient's respiratory condition, 82 patients belonged in the respiratory failure or insufficiency group, and 114 patients were in the respiratory nonfailure group. Before SLB, 26 patients had undergone echocardiography- or computed tomography-guided biopsy or transbronchoscopic biopsy, but no conclusive diagnosis could be obtained. For SLB, VATS was used in $122(62.2 \%)$ patients, and minithoracotomy was 
TABLE 2. Pathologic diagnosis of lung biopsy and effect on patient management

\begin{tabular}{|c|c|c|c|c|}
\hline Pathology & $\begin{array}{c}\text { No. of patients } \\
(n=196)\end{array}$ & $\begin{array}{c}\text { Change in } \\
\text { therapy, no. }(\%)\end{array}$ & $\begin{array}{c}\text { Response to } \\
\text { therapy, no. (\%) }\end{array}$ & $\begin{array}{c}\text { Survival, } \\
\text { no. (\%) }\end{array}$ \\
\hline I. Infectious disease & 60 & $55(91.7)$ & $40(66.7)$ & $41(68.3)$ \\
\hline CMV & $21(5)^{*}$ & $19(90.5)$ & $11(52.4)$ & $11(52.4)$ \\
\hline Tuberculosis & 13 & $13(100)$ & $10(76.9)$ & $10(76.9)$ \\
\hline Organizing pneumonia & 9 & $6(66.7)$ & $5(55.6)$ & $6(66.7)$ \\
\hline Pneumocystis species & 5 & $5(100)$ & $3(60.0)$ & $3(60.0)$ \\
\hline Bacteria or viral pneumonia & 5 & $5(100)$ & $5(100)$ & $5(100)$ \\
\hline Aspergillosis & 4 & $4(100)$ & $3(75.5)$ & $3(75.5)$ \\
\hline Diffuse panbronchiolitis & 2 & $2(100)$ & $2(100)$ & $2(100)$ \\
\hline Cryptococcosis & 1 & $1(100)$ & $1(100)$ & $1(100)$ \\
\hline II. Interstitial pneumonia & 43 & 42 (97.7) & $28(65.1)$ & $26(60.5)$ \\
\hline NSIP & 14 & $13(92.9)$ & $13(92.9)$ & $13(92.9)$ \\
\hline UIP & 10 & $10(100)$ & $6(60.0)$ & $5(50.0)$ \\
\hline AIP & 10 & $10(100)$ & $6(60.0)$ & $6(60.0)$ \\
\hline Honeycomb & 9 & $9(100)$ & $3(33.3)$ & $2(22.2)$ \\
\hline III. Diffuse alveolar damage & 34 & $29(85.3)$ & $21(61.8)$ & $18(52.9)$ \\
\hline IV. Neoplastic disease & 26 & $17(65.4)$ & $14(53.8)$ & $15(57.7)$ \\
\hline Lymphoma & 11 & $8(72.7)$ & $7(63.6)$ & $7(63.6)$ \\
\hline Primary lung cancer & 7 & $4(57.1)$ & $3(42.9)$ & $3(42.9)$ \\
\hline Metastatic lung cancer & 7 & $5(71.4)$ & $4(57.1)$ & $4(57.1)$ \\
\hline Hyalinizing granuloma & 1 & 0 & & 1 \\
\hline V. Autoimmune disease & 16 & $15(93.8)$ & $14(87.5)$ & $14(87.5)$ \\
\hline $\mathrm{BOOP}$ or $\mathrm{BO}$ & 6 & $6(100)$ & $6(100)$ & $6(100)$ \\
\hline Eosinophilic pneumonia & 4 & $4(100)$ & $4(100)$ & $4(100)$ \\
\hline Acute capillaritis & 3 & $3(100)$ & $3(100)$ & $2(66.7)$ \\
\hline Wegener granulomatosis & 2 & $2(100)$ & $1(50.0)$ & $1(50.0)$ \\
\hline Sarcoidosis & 1 & 0 & & 1 \\
\hline VI. Alveolar proteinosis & 6 & $5(83.3)$ & $5(83.3)$ & $5(83.3)$ \\
\hline VII. Lymphangioleiomyomatosis & 4 & 0 & & $4(100)$ \\
\hline VIII. Occupational disease & 5 & & & $5(100)$ \\
\hline Asbestosis & 3 & 0 & & 3 \\
\hline Pneumoconiosis & 1 & 0 & & 1 \\
\hline Siderosis & 1 & 0 & & 1 \\
\hline IX. Pulmonary embolism & 2 & $2(100)$ & $2(100)$ & $2(100)$ \\
\hline
\end{tabular}

CMV, Cytomegalovirus; NSIP, nonspecific interstitial pneumonia; UIP, usual interstitial pneumonia; $A I P$, acute interstitial pneumonia; $B 00 P$ : bronchiolitis obliterans organizing pneumonia; BO, bronchiolitis obliterans. *Mixed infection with Pneumocystis species (3), Aspergillus species (1), bacteria (1).

conducted in $74(37.8 \%)$ patients. The number of biopsy sites was 1 in 143 patients, 2 in 52 patients, and 3 in 1 patient.

The pathologic diagnosis after SLB is shown in Table 2. The distribution of diagnosis was infection $(30.6 \%)$, interstitial pneumonia or fibrosis (21.9\%), diffuse alveolar damage (DAD; 17.3\%), neoplasm (13.3\%), autoimmune diseases $(8.2 \%)$, and others (8.2\%). After open lung biopsy, $165(84.2 \%)$ patients had changes in their therapy, 124 (63.3\%) patients had clinical improvement in their conditions (ie, response to the change in therapy), and 119 $(60.7 \%)$ patients survived until hospital discharge. Five patients eventually died as a result of late complications of long-term steroid use, such as infection, sepsis, or upper gastrointestinal tract bleeding, despite initial improvement first being noted. For the patients who had a change in therapy after SLB, the rate of patient survival (72.1\%) was significantly higher than that of those who had no change $(51.6 \%, P<.05)$. The rates of change in therapy, response to therapy, and patient survival in different groups of diagnoses did not show any significant differences. Comparison between immunocompromised and immunocompetent patients showed that diagnosis of infection was significantly higher $(P<.01)$ in the former group $(41.2 \%$ vs $20.2 \%)$. There were no significant differences in the rates of change in therapy, response to therapy, and patient survival between these 2 groups (Table 3 ).

Comparison between the respiratory failure and nonfailure groups showed that there were no significant differences in the distribution of diagnosis and the rate of change in therapy. However, the rates of response to therapy and patient survival were significantly lower in the respiratory 
TABLE 3. Comparison between immunocompromised and immunocompetent patients

\begin{tabular}{|c|c|c|c|c|c|c|c|c|}
\hline \multirow[b]{2}{*}{ Diagnosis } & \multicolumn{4}{|c|}{ Immunocompromised $(\mathbf{n}=97)$} & \multicolumn{4}{|c|}{ Immunocompetent (n = 99) } \\
\hline & $\begin{array}{c}\text { No. of } \\
\text { patients }\end{array}$ & $\begin{array}{c}\text { Change in } \\
\text { therapy, no. (\%) }\end{array}$ & $\begin{array}{c}\text { Response to } \\
\text { therapy, no. (\%) }\end{array}$ & $\begin{array}{c}\text { Survival, } \\
\text { no. }(\%)\end{array}$ & $\begin{array}{c}\text { No. of } \\
\text { patients }\end{array}$ & $\begin{array}{c}\text { Change in } \\
\text { therapy, no. }(\%)\end{array}$ & $\begin{array}{c}\text { Response to } \\
\text { therapy, no. (\%) }\end{array}$ & $\begin{array}{c}\text { Survival, } \\
\text { no. }(\%)\end{array}$ \\
\hline Infectious disease & 40 & $38(95.0)$ & $26(65.0)$ & $25(62.5)$ & 20 & $17(85.0)$ & $14(70.0)$ & $14(70.0)$ \\
\hline CMV & 18 & $17(94.4)$ & $10(55.6)$ & $9(50.0)$ & 3 & $2(66.7)$ & $1(33.3)$ & $1(33.3)$ \\
\hline Tuberculosis & 6 & $6(100)$ & $4(66.7)$ & $4(66.7)$ & 7 & $7(100)$ & $6(85.7)$ & $6(85.7)$ \\
\hline $\begin{array}{l}\text { Pneumocystis } \\
\text { species }\end{array}$ & 5 & $5(100)$ & $3(60.0)$ & $3(60.0)$ & 0 & & & \\
\hline Others & 11 & $10(90.9)$ & $9(81.8)$ & $9(81.8)$ & 10 & $8(80.0)$ & $7(70.0)$ & $7(70.0)$ \\
\hline $\begin{array}{l}\text { Interstitial } \\
\quad \text { pneumonia }\end{array}$ & 21 & $20(95.2)$ & $16(76.2)$ & $15(71.4)$ & 22 & $22(100)$ & $12(54.5)$ & $10(45.5)$ \\
\hline NSIP & 11 & $10(90.9)$ & $10(90.9)$ & $10(90.9)$ & 3 & $3(100)$ & $3(100)$ & $3(100)$ \\
\hline Honeycomb & 6 & $6(100)$ & $2(33.3)$ & $2(33.3)$ & 3 & $3(100)$ & $1(33.3)$ & $0(0)$ \\
\hline UIP & 2 & $2(100)$ & $2(100)$ & $1(50.0)$ & 8 & $8(100)$ & $4(50.0)$ & $4(50.0)$ \\
\hline AIP & 2 & $2(100)$ & $2(100)$ & $2(100)$ & 8 & $8(100)$ & $4(50.0)$ & $3(37.5)$ \\
\hline $\begin{array}{c}\text { Diffuse alveolar } \\
\text { damage }\end{array}$ & 20 & $17(85.0)$ & $12(60.0)$ & $8(40.0)$ & 14 & $12(85.7)$ & $9(64.3)$ & $8(57.1)$ \\
\hline $\begin{array}{c}\text { Autoimmune } \\
\text { disease }\end{array}$ & 4 & $4(100)$ & $3(75.0)$ & $2(50.0)$ & 12 & 11 (91.7) & 11 (91.7) & 11 (91.7) \\
\hline $\begin{array}{l}\text { Neoplastic } \\
\text { disease }\end{array}$ & 8 & $5(62.5)$ & $4(50.0)$ & $4(50.0)$ & 18 & $12(66.7)$ & $10(55.6)$ & $10(55.6)$ \\
\hline
\end{tabular}

$C M V$, Cytomegalovirus; NSIP, nonspecific interstitial pneumonia; UIP, usual interstitial pneumonia; $A I P$, acute interstitial pneumonia.

failure group $(51.2 \%$ and $41.5 \%)$ than in the nonfailure group $(71.9 \%$ and $78.1 \%, P<.05)$. The differences were mainly observed in the groups of patients with infection (39.1\% vs $83.8 \%$ and $34.8 \%$ vs $83.8 \%, P<.01)$ and interstitial pneumonia $(47.6 \%$ vs $81.8 \%$ and $42.9 \%$ vs
77.3\%, $P<.05$; Table. 4) Thirty-two patients had earlier undergone BMT for hematologic malignancies or myelosuppressive diseases. The results of SLB for diffuse pulmonary lesions in these patients revealed inflammatory or immunologic diseases in 16 patients, infectious diseases in

TABLE 4. Comparison between patients with and without respiratory failure

\begin{tabular}{|c|c|c|c|c|c|c|c|c|}
\hline \multirow[b]{2}{*}{ Diagnosis } & \multicolumn{4}{|c|}{ Respiratory failure } & \multicolumn{4}{|c|}{ Respiratory nonfailure } \\
\hline & $\begin{array}{c}\text { No. of } \\
\text { patients }\end{array}$ & $\begin{array}{c}\text { Change in } \\
\text { therapy, no. }(\%)\end{array}$ & $\begin{array}{c}\text { Response to } \\
\text { therapy, no. }(\%)\end{array}$ & $\begin{array}{c}\text { Survival, } \\
\text { no. }(\%)\end{array}$ & $\begin{array}{c}\text { No. of } \\
\text { patients }\end{array}$ & $\begin{array}{c}\text { Change in } \\
\text { therapy, no. }(\%)\end{array}$ & $\begin{array}{c}\text { Response to } \\
\text { therapy, no. (\%) }\end{array}$ & $\begin{array}{c}\text { Survival, } \\
\text { no. }(\%)\end{array}$ \\
\hline Infectious disease & 23 & $21(91.3)$ & $9(39.1)$ & $8(34.8)$ & 37 & $34(91.9)$ & 31 (93.8) & 31 (83.8) \\
\hline CMV & 11 & $10(90.9)$ & $4(36.4)$ & $3(27.3)$ & 10 & $9(90.0)$ & $7(70.0)$ & $7(70.0)$ \\
\hline $\begin{array}{l}\text { Pneumocystis } \\
\text { species }\end{array}$ & 4 & $4(100)$ & $2(50.0)$ & $2(50.0)$ & 1 & $1(100)$ & $1(100)$ & $1(100)$ \\
\hline Tuberculosis & 4 & $4(100)$ & $2(50.0)$ & $2(50.0)$ & 9 & $9(100)$ & $8(88.9)$ & $8(88.9)$ \\
\hline Others & 4 & $3(75.0)$ & $1(33.3)$ & $1(33.3)$ & 17 & $15(88.2)$ & $15(88.2)$ & $15(88.2)$ \\
\hline $\begin{array}{c}\text { Interstitial lung } \\
\text { disease }\end{array}$ & 21 & $20(95.2)$ & $10(47.6)$ & $9(42.0)$ & 22 & $22(100)$ & $18(81.8)$ & $17(77.3)$ \\
\hline NSIP & 6 & $5(83.3)$ & $5(83.3)$ & $5(83.3)$ & 8 & $8(100)$ & $8(100)$ & $8(100)$ \\
\hline AIP & 6 & $6(100)$ & $3(50.0)$ & $3(50.0)$ & 4 & $4(100)$ & $3(75.0)$ & $3(75.0)$ \\
\hline Honeycomb & 5 & $5(100)$ & $0(0)$ & $0(0)$ & 4 & $4(100)$ & $3(75.0)$ & $2(50.0)$ \\
\hline UIP & 4 & $4(100)$ & $2(50.0)$ & $1(25.0)$ & 6 & $6(100)$ & $4(66.7)$ & $4(66.7)$ \\
\hline $\begin{array}{l}\text { Diffuse alveolar } \\
\text { damage }\end{array}$ & 24 & 21 (87.5) & $15(62.5)$ & $10(41.7)$ & 10 & $8(80.0)$ & $6(60.0)$ & $6(60.0)$ \\
\hline $\begin{array}{l}\text { Autoimmune } \\
\text { disease }\end{array}$ & 5 & $5(100)$ & $4(80.0)$ & $4(80.0)$ & 11 & $11(100)$ & $10(90.0)$ & $9(81.8)$ \\
\hline $\begin{array}{c}\text { Neoplastic } \\
\text { disease }\end{array}$ & 5 & $3(60.0)$ & $1(20.0)$ & $1(20.0)$ & 21 & $14(66.7)$ & $13(61.9)$ & 13 (61.9) \\
\hline
\end{tabular}

$C M V$, Cytomegalovirus; NSIP, nonspecific interstitial pneumonia; AIP, acute interstitial pneumonia; UIP, usual interstitial pneumonia. 
TABLE 5. Result of open lung biopsy in $\mathbf{3 2}$ bone marrow transplant recipients

\begin{tabular}{lc}
\hline Diagnosis & $\begin{array}{c}\text { No. of } \\
\text { patients (\%) }\end{array}$ \\
\hline I. Inflammatory or immunologic & $16(50.0)$ \\
Interstitial pneumonia & 10 \\
Diffuse alveolar damage & 3 \\
Organizing pneumonia & 1 \\
Bronchiolitis obliterans & 1 \\
Acute capillaritis & 1 \\
II. Infectious & $13(40.6)$ \\
Cytomegalovirus & 10 \\
Tuberculosis & 2 \\
Pneumocystis species & 1 \\
III. Neoplastic & $3(9.4)$ \\
Lymphoma & 2 \\
PTLD & 1 \\
\hline
\end{tabular}

PTLD, Posttransplantation lymphoproliferative disorder.

13 patients, and lymphoma or lymphoproliferative disorder in 3 patients. Cytomegalovirus pneumonia accounted for $76.9 \%(10 / 13)$ of infections (Table 5). The result of treatment of the infectious group showed a $38.5 \%(5 / 13)$ rate in both response to therapy and patient survival, which was comparatively lower than rates of $93.8 \%(15 / 16)$ and $81.3 \%$ $(13 / 16)$ for inflammatory and immunologic diseases $(P<$ .01 and $P<.05)$.

Pulmonary tuberculosis accounted for 13 of 60 of the infections. The prevalence was almost the same in the immunocompromised and nonimmunocompromised groups. Among the 21 patients with a clinical diagnosis of tuberculosis before SLB, only 3 had had a correct pathologic diagnosis. In the other 10 patients with a final diagnosis of tuberculosis, tuberculosis was not suspected before SLB.

In this series, calculating from the date of onset of the symptom to the date of SLB, 134 patients underwent SLB before 30 days, and 62 patients underwent SLB after 30 days. There was no significant difference in the rate of change in therapy, response to therapy, and patient survival between these 2 groups.

In this study there was no surgical mortality directly related to the procedure. Thirteen $(6.6 \%)$ patients had surgical morbidities, which included prolonged air leakage ( $\geq 7$ days) in 11 patients ( 7 in the minithoracotomy group and 4 in the VATS group), hemothorax in 1 patient, and acute myocardial infarction in 1 patient. Overall, 130 patients survived until hospital discharge. The in-hospital mortality rate was $33.7 \%$ (66/196), and the 30-day mortality rate was $24.0 \%(47 / 196)$.

\section{Discussion}

Although nonspecific diagnosis, such as DAD and interstitial pneumonia, accounted for a portion $(39.3 \%)$ of pathologic diagnoses in this series, for most patients (60.7\%), a specific diagnosis could only be made after SLB. Infection, neoplastic disease, and autoimmune disease were among the most common specific diagnoses in patients with DPD. This result is similar to most of the recently reported series. ${ }^{1,7,9-11}$ The specific causes of DAD usually cannot be determined from the histologic findings. It can be identified through the information from clinical history and laboratory data. In our experience of patients with DAD, once infectious causes could be excluded by means of histologic examination and tissue culture, corticosteroid therapy was added if the condition of the patient did not improve after 1 to 2 weeks of antibiotic treatment and respiratory support. For patients with a diagnosis of interstitial pneumonia, intravenous corticosteroid therapy (40-80 mg of methylprednisolone every 6 hours) began after SLB. Among the different types of interstitial pneumonia, the rate of response to therapy and patient survival in nonspecific interstitial pneumonia was comparatively higher. Generally, the rate of change in therapy, response to therapy, and patient survival in patients with a diagnosis of DAD or interstitial pneumonia was similar to those of patients with a specific diagnosis. This result is similar to some of the previous reports. ${ }^{1,2,12}$ In addition, the rate of change in therapy in this series is considerably higher than that of other studies. ${ }^{7}$ The beneficial effect of change in therapy on patient survival was more obvious than in other reports. ${ }^{1,3,9}$ This discrepancy can be explained by the fact that we seldom performed a transbronchoscopic lavage or biopsy before SLB in patients with undiagnosed DPD. The diagnostic yield of bronchoscopic diagnostic procedure is considerably lower than that of $\mathrm{SLB}^{4}$ and is not without risk, especially in patients using mechanical ventilation or with a bleeding tendency. ${ }^{13,14}$ In this series of SLB, no operative mortality and only a few morbidities were noted. Moreover, a less invasive VATS could have been used for two thirds of the patients. Therefore, SLB was considered earlier if the condition of the patients with DPD deteriorated.

Infection was the most common diagnosis in immunocompromised patients, and the rates of change in therapy and patient survival were similar to those of immunocompetent patients. The result was similar to those seen in some of the previous reports. ${ }^{2,9}$ Although the number of infectious causes was relatively low in immunocompetent patients, the suggestion of a steroid trial before SLB in immunocompetent patients should be made with caution because infection still remains one of the most common causes of diffuse pulmonary infiltrate. ${ }^{7}$

In this series, patients with respiratory failure had a considerably lower rate of response to therapy and survival than did patients without failure, which is similar to 
results seen in other studies. ${ }^{1,3,9,10}$ We believe that the compromised condition, along with irreversible inflammatory changes in patients with respiratory failure, make the diagnosis and treatment of DPD more difficult and subsequently lead to mortality. It is suggested that patients with undiagnosed DPD should be considered for SLB before the development of respiratory failure.

The result of SLB in patients with BMT showed a high incidence of nonspecific diagnoses, such as interstitial pneumonia or DAD. The cause was unclear but might be related to previous irradiation, chemotherapy, or both; to an undiagnosed viral infection; or to graft-versus-host disease. ${ }^{15}$ This result is similar to the results of recent reports. ${ }^{16-18}$ Nevertheless, the rate of response to change of therapy and patient survival in this nonspecific diagnosis group is obviously better than in those with a specific diagnosis, mostly because of cytomegalovirus infection. This result is different from some previous reports. ${ }^{16,18}$ The reason for such a difference is possibly the inadequate surveillance for cytomegalovirus after BMT in our hospital and also different spectrums of histologic diagnosis in this series. ${ }^{19}$ Although it is generally accepted that the prognosis after SLB in patients with BMT is obviously poor, our study did not show the same result compared with other groups of patients. ${ }^{17,18}$ The difference might be explained by the principle of early SLB, accurate diagnosis, and prompt treatment in patients with BMT with undiagnosed DPD in our institution.

Pulmonary tuberculosis remains one of the most common infectious diseases in Taiwan. ${ }^{20}$ In this study we have found that pulmonary tuberculosis presenting with DPD was sometimes difficult to diagnose by means of sputum examination and imaging studies, such as chest roentgenography and computed tomography. Pulmonary tuberculosis presenting with DPD could occur in both immunocompromised and immunocompetent patients. SLB is very helpful for an accurate diagnosis of patients with pulmonary tuberculosis presenting with DPD.

VATS was conducted in two thirds of the SLBs. It provided good vision of the whole pleural cavity and a greater selection of biopsy sites. It is generally accepted that VATS biopsy reduces postoperative pain and disability, causes fewer operative scars, and is equally effective in obtaining histologic diagnosis. ${ }^{21,22}$ Therefore, we believe that VATS should be considered as the first priority for SLB. However, if the patient's condition will not allow him or her to tolerate single-lung ventilation or if pleural adhesion is noted during the operation, VATS should not be used for SLB.

It has been reported that SLB results in considerable postoperative morbidities and mortalities, which might run as high as $50 \% .^{8}$ In this study only a few postoper- ative complications were noted, and no operative death occurred directly relating to the procedure. Most of the hospital mortality was caused by disease progression, secondary infection, or complications of the treatment.

In conclusion, SLB is an accurate diagnostic tool for DPD with minimal operative morbidity and mortality. It is helpful for a significant portion of patients in the aspects of change in therapy and response to therapy. It should be considered earlier in patients with undiagnosed DPD, especially when the respiratory condition of the patient is deteriorating.

\section{References}

1. Warner DO, Warner MA, Divertie MB. Open lung biopsy in patients with diffuse pulmonary infiltrates and acute respiratory failure. Am Rev Respir Dis. 1988;137:90-4.

2. Walker WA, Cole FH Jr, Khandekar A, Mahfood SS, Watson DC. Does open lung biopsy affect treatment in patients with diffuse pulmonary infiltrates? J Thorac Cardiovasc Surg. 1989;97:534-40.

3. Temes RT, Joste NE, Qualls CR, Allen NL, Crowell RE, Dox HA, et al. Lung biopsy: is it necessary. J Thorac Cardiovasc Surg. 1999;118: 1097-100.

4. Burt ME, Flye MW, Webber BL, Wesley RA. Prospective evaluation of aspiration needle, cutting needle, transbronchial, and open lung biopsy in patients with pulmonary infiltrates. Ann Thorac Surg. 1981; 32:146-53.

5. Curley FJ, Johal JS, Burke ME, Fraire AE. Transbronchial lung biopsy: Can specimen quality be predicted at the time of biopsy? Chest. 1998;113:1037-41.

6. Rao VK, Ritter J, Kollef MH. Utility of transbronchial biopsy in patients with acute respiratory failure: a postmortem study. Chest. 1998;114:549-55.

7. Kramer MR, Berkman N, Mintz B, Godfrey S, Saute M, Amir G. The role of open lung biopsy in the management and outcome of patients with diffuse lung disease. Ann Thorac Surg. 1998;65:198-202.

8. Hiatt JR, Gong H, Mulder DG, Ramming KP. The value of open lung biopsy in the immunosuppressed patient. Surgery. 1982;92:285-91.

9. Bove P, Ranger W, Pursel S, Glover J, Bove K, Bendick P. Evaluation of outcome following open lung biopsy. Ann Surg. 1994;60:564-70.

10. LoCicero J III. Does every patient with enigmatic lung disease deserve a lung biopsy? The continuing dilemma. Chest. 1994;106:706-8.

11. Canver CC, Mentzer RM Jr. The role of open lung biopsy in early and late survival of ventilator-dependent patients with diffuse idiopathic lung disease. J Cardiovasc Surg (Torino). 1994;35:151-5.

12. Robbins BE, Steiger Z, Wilson RF, Ratanath V, Karanes C, Bander J, et al. Diagnosis of acute diffuse pulmonary infiltrates in immunosuppressed patients by open lung biopsy of the lung. Surg Gynecol Obstet. 1992;175:8-12.

13. Ellis JH Jr. Transbronchial lung biopsy via the fiberoptic bronchoscope, experience with 107 consecutive cases and comparison with bronchial brushing. Chest. 1975;68:524-32.

14. Papin TA, Lynch JP III, Weg JG. Transbronchial biopsy in the thrombocytopenic patient. Chest. 1985;88:549-52.

15. Katzenstein A-LA. Immunological lung disease. In: Katzenstein A-LA, editor. Katzenstein and Askin's surgical pathology of nonneoplastic lung disease. 3rd ed. Philadelphia: WB Saunders: 1997; p. 138-67.

16. White DA, Wong PW, Downey R. The utility of open lung biopsy in patients with hematologic malignancies. Am J Respir Crit Care Med. 2000;161:723-9.

17. Snyder CL, Ramsay NK, Mc Glave PB, Ferrell KL, Leonard AS. Diagnostic open-lung biopsy after bone marrow transplantation. $J \mathrm{Pe}$ diatr Surg. 1990;25:871-7.

18. Shorter NA, Ross AJ III, August C, Schnaufer L, Zeigler M, Templeton JM Jr, et al. The usefulness of open-lung biopsy in the pediatric bone marrow transplant population. J Pediatr Surg. 1988;23:533-7. 
19. Wang JY, Chang YL, Lee LN, Chen JH, Tang JL, Yang PC, et al. Diffuse pulmonary infiltrates after bone marrow transplantation: the role of open lung biopsy. Ann Thorac Surg. 2004;78:267-72.

20. Department of Health, the Executive Yuan, ROC. Health and vital statistics-1, 1997. Taipei, Republic of China; 1998. p. 7.
21. Ferguson MK. Thoracoscopy for diagnosis of diffuse lung disease. Ann Thorac Surg. 1993;56:694-6.

22. Carnochan FM, Walker WS, Cameron EWJ. Efficacy of video assisted thoracoscopic lung biopsy: an historical comparison with open lung biopsy. Thorax. 1994;49:361-3.

To assure fairness to authors submitting work for consideration in The Journal of Thoracic and Cardiovascular Surgery, a mechanism exists for managing conflicts of interest. The editor and each of the section editors complete a "Conflict of Interest" form that identifies any and all relationships with commercial and other academic entities. When the editor has a potential conflict because of a relationship with another entity or author, the editor appoints an alternate editor from among the section editors or editorial board members who assumes the entire responsibility for final decisions on the manuscript in question. The editor does not read the reviews that are submitted nor engage in discussing the manuscript prior to the final decision. When the conflict of interest involves a section editor, a "guest section editor" is appointed who fills the role normally played by the conflicted section editor. All members of the editorial board and reviewers are asked to indicate any conflict of interest when they agree to review a manuscript. 